\title{
The impact of a bodyweight and physical activity intervention (BeWEL) initiated through a national colorectal cancer screening programme: randomised controlled trial
}

\author{
(c) $\begin{gathered}\text { (1) (8) } \\ \text { ay }\end{gathered}$
}

Annie S Anderson professor of public health nutrition ${ }^{1}$, Angela M Craigie lecturer in cancer prevention ${ }^{1}$, Stephen Caswell research fellow ${ }^{1}$, Shaun Treweek professor ${ }^{2}$, Martine Stead deputy director $^{3}$, Maureen Macleod research fellow ${ }^{1}$, Fergus Daly biostatistics team lead ${ }^{4}$, Jill Belch NHS Tayside R\&D director, codirector Medical Research Institute ${ }^{5}$, Jackie Rodger colorectal specialist nurse $^{6}$, Alison Kirk senior lecturer ${ }^{7}$, Anne Ludbrook professor in health economics ${ }^{8}$, Petra Rauchhaus clinical trials statistician ${ }^{9}$, Patricia Norwood research fellow ${ }^{8}$, Joyce Thompson consultant in public health nutrition ${ }^{10}$, Jane Wardle professor in clinical psychology, and director ${ }^{11}$, Robert J C Steele head of cancer research, and professor of surgery ${ }^{1}$

\footnotetext{
${ }^{1}$ Centre for Research into Cancer Prevention and Screening, Cancer Division, Medical Research Institute, Ninewells Medical School, Dundee, UK; ${ }^{2}$ Health Services Research Unit, University of Aberdeen, Aberdeen, UK; ${ }^{3}$ Institute for Social Marketing, University of Stirling, Stirling, UK; ${ }^{4} F r o n t i e r$ Science (Scotland), Kincraig, Kingussie, Inverness-shire, UK; ${ }^{5}$ Vascular Diseases Research Unit, Medical Research Institute, Ninewells Medical School, Dundee, UK; ${ }^{6}$ Ninewells Hospital and Medical School, Dundee, UK; ${ }^{7}$ Physical Activity for Health Research Group, School of Psychological Sciences and Health, University of Strathclyde, Glasgow, UK; ${ }^{8}$ Health Economics Research Unit, University of Aberdeen, Aberdeen, UK; ${ }^{9} \mathrm{Tayside}$ Clinical Trials Unit, Tayside Medical Science Centre, Ninewells Hospital and Medical School, Dundee, UK; ${ }^{10}$ Directorate of Public Health, NHS Tayside, Kings Cross Hospital, Dundee, UK; ${ }^{11}$ Health Behaviour Research Centre, Institute of Epidemiology and Public Health, University College London, London, UK
}

\begin{abstract}
Objective To evaluate the impact of a diet and physical activity intervention (BeWEL) on weight change in people with a body mass index $>25$ weight $(\mathrm{kg}) /$ height $(\mathrm{m})^{2}$ at increased risk of colorectal cancer and other obesity related comorbidities.

Design Multicentre, parallel group, randomised controlled trial.

Setting Four Scottish National Health Service health boards.

Participants 329 overweight or obese adults (aged 50 to 74 years) who had undergone colonoscopy after a positive faecal occult blood test result, as part of the national bowel screening programme, and had a diagnosis of adenoma confirmed by histopathology. 163 were randomised to intervention and 166 to control.

Intervention Participants were randomised to a control group (weight loss booklet only) or 12 month intervention group (three face to face visits with a lifestyle counsellor plus monthly 15 minute telephone calls).
\end{abstract}

A goal of $7 \%$ reduction in body weight was set and participants received a personalised energy prescription $(2508 \mathrm{~kJ}$ (600 kcal) below that required for weight maintenance) and bodyweight scales. Motivational interviewing techniques explored self assessed confidence, ambivalence, and personal values concerning weight. Behavioural strategies included goal setting, identifying intentions of implementation, self monitoring of body weight, and counsellor feedback about reported diet, physical activity, and weight change.

Main outcome measures The primary outcome was weight change over 12 months. Secondary outcomes included changes in waist circumference, blood pressure, fasting cardiovascular biomarkers, and glucose metabolism variables, physical activity, diet, and alcohol consumption

Results At 12 months, data on the primary outcome were available for $148(91 \%)$ participants in the intervention group and $157(95 \%)$ in the control group. Mean weight loss was $3.50 \mathrm{~kg}$ (SD 4.91) (95\% confidence 
interval 2.70 to 4.30$)$ in the intervention group compared with $0.78 \mathrm{~kg}$ (SD 3.77) (0.19 to 1.38) in the control group. The group difference was $2.69 \mathrm{~kg}$ (95\% confidence interval 1.70 to 3.67). Differences between groups were significant for waist circumference, body mass index, blood pressure, blood glucose level, diet, and physical activity. No reported adverse events were considered to be related to trial participation.

Conclusions Significant weight loss can be achieved by a diet and physical activity intervention initiated within a national colorectal cancer screening programme, offering considerable potential for risk reduction of disease in older adults.

Trial registration Current Controlled Trials ISRCTN53033856.

\section{Introduction}

Colorectal cancer is the third most common cancer and cause of cancer related death in the United Kingdom. ${ }^{1}$ Most cases $(95 \%)$ occur in people aged over 50 , who often have other lifestyle related comorbidities, such as obesity, type 2 diabetes mellitus, and cardiovascular disease. ${ }^{2}{ }^{3}$ These diseases share common risk factors, including increased waist circumference, altered glucose metabolism, and abnormal lipid levels. ${ }^{45}$ Consistent with findings for cardiovascular disease and type 2 diabetes mellitus, ${ }^{67}$ high levels of body fat (body mass index $>23$ (weight $(\mathrm{kg}) /$ height $\left.(\mathrm{m})^{2}\right)$ ) or a large waist circumference are associated with an increased risk of cancer. ${ }^{8}$ Recent UK estimates on cancer preventability indicate that $12 \%$ of colorectal cancers could be prevented by increased physical activity, $14 \%$ by the avoidance of excess weight, and $34 \%$ by changes in diet and alcohol intake. ${ }^{9}$ Thus several modifiable risk factors can be identified and tackled with potential benefit to risk of colorectal cancer, and proved benefit on risk reduction of type 2 diabetes mellitus and cardiovascular disease.

The general public perceive health professionals as experts in matters relating to disease prevention and management. Thus, individual communications with patients on behaviour change can help to endorse the messages of public health campaigns. The National Health Service colorectal cancer screening programme ${ }^{10}$ is increasing the identification of adenomas and offers a timely opportunity for expert health professionals to offer advice on risk factor reduction to older, overweight adults who had an adenoma to minimise the risk of colorectal cancer and other obesity related comorbidities. Surveillance colonoscopy is offered to patients who have had adenomas, but procedures may still miss adenomas, and several studies have reported interval cancers diagnosed between examinations. ${ }^{11} 12$ Current evidence suggests that the risk of new adenomas is around $40 \%$ after three years, although this may be higher in obese men. ${ }^{13}$ A Japanese study of 16500 people found a significant reduction in adenoma recurrence in those who had lost weight in the follow-up period compared with those who maintained or gained weight. ${ }^{14}$ While colonoscopy may reduce the risk of subsequent cancer, the underlying lifestyle factors that influence the development of new adenomas and other obesity related conditions remain to be addressed.

The setting of colorectal cancer screening has been described as an unexplored opportunity for endorsing changes in health behaviours. ${ }^{15}$ Behaviour change programmes that target higher risk groups may be more effective than those targeting the population at large; thus adults who have been found to have adenomas may be more motivated to engage with lifestyle interventions. ${ }^{16}$ However, patients need to be aware of the relevant risk factors and relate these to current personal behaviours before the "teachable moment" opportunity can be perceived as relevant. One study noted that while understanding of the relation between smoking and lung cancer is shared and accepted there is much less awareness of the relation between colorectal cancer and lifestyle. ${ }^{17}$ These findings have been echoed by other researchers, who found that patients with high risk colorectal adenomas believed that their current behaviour was appropriate or that they perceived no risk between health behaviour and disease outcome. ${ }^{18}$ These authors suggest that intervention programmes need to be tailored to individuals, concentrate on the paucity of knowledge about the causes of colon cancer in the general population, and highlight motivational factors. In addition, the lack of advocacy on lifestyle change in these settings may endorse poor health behaviours as it is recognised that the absence of guidance may produce a "health certificate effect" so that patients who receive negative results may feel no need to modify their lifestyle. ${ }^{19}$ This situation may be particularly relevant for body weight, where the lack of guidance to visibly obese patients may signal lack of medical concern.

We evaluated the impact of a diet and physical activity intervention programme (BeWEL) on bodyweight change in overweight or obese people attending routine NHS colorectal cancer screening clinics who had had colorectal adenomas removed but were at risk of developing further obesity related conditions.

\section{Methods}

The study was a multicentre, 1:1 parallel group randomised controlled trial conducted in Scotland, United Kingdom from November 2010 to May 2013. A detailed study protocol has been published..$^{20}$

\section{Sample size}

The sample size calculation was based on the primary outcome of change in body weight at 12 months. A $7 \%$ weight loss at 12 months has been shown to be clinically effective in reducing the risk of diabetes. ${ }^{21}$ Therefore to show a $7 \%$ weight loss with $80 \%$ power we estimated that 133 participants would be required to complete each arm of the study (266 in total). Expected recruitment rates and mean body weight at baseline $(85.4 \mathrm{~kg}$ (SD 17.3)) were based on a previous study in this population subgroup, Bowel Health to Better Health. ${ }^{22}$ Thus, to achieve the recruitment target we estimated that a pool of 558 patients would be required from which to recruit, to allow for an expected eligibility rate of $81 \%(n=452)$, a recruitment rate of $70 \%$ $(\mathrm{n}=316)$, and a subsequent drop-out rate of $16 \%(\mathrm{n}=266)$.

\section{Participants and recruitment}

We approached all screening participants in Tayside, Forth Valley, and Ayrshire and Arran health boards between November 2010 and April 2012 (and between January and April 2012 in Greater Glasgow and Clyde health board) who had a diagnosis of adenoma confirmed by histopathology following a positive faecal occult blood test result, as part of the national bowel screening programme.

Eligible participants were those aged 50 to 74 years (in line with the Scottish age criteria for routine colorectal cancer screening) who had undergone polypectomy for adenoma, had a body mass index $>25$, and were able to undertake physical activity and provide informed consent. Exclusion criteria were pregnancy, insulin dependent diabetes mellitus, and any cancer diagnosis.

After screening colonoscopy, all patients received a letter confirming the colonoscopy results. If an adenoma was diagnosed, a letter from the lead consultant highlighting the relation between lifestyle and adenoma recurrence and endorsing 
the BeWEL study was sent with the results. Two weeks later a BeWEL invitation letter and brief information leaflet were sent from the study team to potential participants. A research nurse telephone screened those who responded positively and, if eligible, posted them the full information leaflet and invited them to the local study centre to provide written informed consent and undergo baseline measures. At the end of this meeting, all participants (intervention and control) were given a copy of the British Heart Foundation booklet So You Want To Lose Weight For Good. ${ }^{23}$

\section{Baseline and follow-up measures}

The study duration was 12 months. We recorded several objective measures at baseline, three months, and 12 months: height $(\mathrm{cm})$, measured with a portable stadiometer (Leicester height measure; Seca, Birmingham, UK); body weight (kg), measured with the participant wearing indoor clothing and no shoes, using a calibrated digital scale (Seca 877) waist circumference $(\mathrm{cm})$, measured with a measuring tape (Seca 201) with the participant in the standing position and the tape positioned midway between the lateral lower rib margin and the iliac crest. If these landmarks could not be identified, the measurement was taken at the level of the umbilicus. Two measurements were taken after exhalation and the mean recorded. Blood pressure was measured after the participant had been seated for five minutes with the arm supported at heart level, using an appropriately sized cuff on the left arm and a digital blood pressure monitor (BP 3BTO; Microlife AG Swiss, Widnau, Switzerland). We took two readings, or three if these two were raised, one or more minutes apart, and reported the mean.

Fasting blood samples were obtained by venepuncture and analysed by standard techniques in the NHS laboratories to evaluate levels of cholesterol (total, low density lipoprotein cholesterol, and high density lipoprotein cholesterol), triglycerides, glucose, glycated haemoglobin, and insulin. We used homeostasis model assessment to assess insulin sensitivity ([insulin $(\mu \mathrm{U} / \mathrm{mL}) \times$ glucose $(\mathrm{mmol} / \mathrm{L})] / 22.5){ }^{24}$

Physical activity levels were measured using a SenseWear armband (BodyMedia, Pittsburgh, PA) worn on the upper arm for seven days. This provided an objective and consistent measure of daily energy expenditure, step count, and minutes of moderate (3-5 metabolic equivalent of task, METs) and vigorous ( $\geq 6$ METs) activity. ${ }^{25}$

An interviewer administered questionnaire was used to record self reported dietary intake and frequency of alcohol consumption.

We used the dietary instrument for nutrition education questionnaire to assign participants scores for fibre, fat, and unsaturated fat. ${ }^{26}$ The fibre score (range 3-88) was based on the frequency of intake of bread, rice, potatoes, pasta, and other starchy foods, and fruit and vegetables (including beans and lentils). A score of less than 30 (low) is equivalent to a fibre intake of $20 \mathrm{~g} /$ day or less, whereas a score of more than 40 (high) is equivalent to an intake of more than $30 \mathrm{~g} /$ day. The fat score (range 7->77) was based on intakes of foods that contribute substantially to fat intake - that is, dairy foods, meat, processed meat, fish, fried foods, sweet and savoury snacks, and fat spreads. A score of less than 30 is equivalent to a fat intake of $83 \mathrm{~g} /$ day or less $(<35 \%$ of total energy intake for an average woman). The unsaturated fat score (range 3-12) was based on the type of fats used, with a score of up to 5 considered low, and a score of 10 or more considered high.
We used a modification of the Cappuccio and colleagues two-item questionnaire ${ }^{27}$ to assess daily portions of fruit and vegetables. Participants were asked "How many pieces of fruit and vegetables (excluding potatoes) do you eat —of any sort—on a typical day?" Fruit and vegetable portions were reported separately, and fruit and vegetable juices were counted as a maximum of one portion a day only. Portions sizes were illustrated using show cards, as defined by NHS guidance on portion size. ${ }^{28}$

Frequency of consumption of sugary drinks (excluding diet, low calorie drinks and fresh fruit juice) were self reported using nine frequency categories. To identify changes in frequency of typical alcohol consumption (on week days and weekends) we used questions from the alcohol use disorders inventory test. ${ }^{29}$

At baseline we collected sociodemographic data on age, sex, ethnicity, marital status, education, employment, and area of residence (to identify Scottish index of multiple deprivation ${ }^{30}$ ). No information on medical history was collected, but we noted current drug usage.

\section{Randomisation}

Following the baseline visit, eligible people who provided consent were randomised 1:1 to receive either the diet and physical activity intervention (BeWEL) or usual care. A statistician, independent of the analysis of study outcomes, had previously generated a randomisation list (site specific identification numbers and group allocation) by using a permuted block technique, with block sizes of four and eight, stratified by trial site. This list was emailed to the study administrator and trial manager. Research nurses allocated participants a site specific identification number sequentially and notified the study administrator on completion of baseline measures for each participant. The study administrator then identified the participant's group allocation from the randomisation list and notified the lifestyle counsellor of participants allocated to the intervention group or sent the weight loss booklet to participants allocated to usual care.

\section{Blinding}

The study team, including the research nurses, were blinded to the participant's group allocation until completion of the primary outcome analysis. Exceptions were the trial manager, study administrator, lifestyle counsellors, and participants who could not be blinded owing to the nature of the intervention. None of these unblinded staff had a role in data analysis.

\section{Intervention group}

Within two weeks of obtaining the baseline measures, participants randomised to the intervention group participated in the 12 month BeWEL programme. This was delivered by trained lifestyle counsellors in three, one hour, one to one visits during the first three months (including spouse or friend when possible), followed by nine, monthly, 15 minute telephone consultations. Thus each participant had a total of 5.25 hours contact over a 12 month period. Motivational interviewing techniques were utilised to explore self assessed confidence, ambivalence, and personal values concerning weight change. ${ }^{31}$ All intervention participants were set a target goal of a $7 \%$ reduction in body weight and provided with a personalised energy prescription of $2508 \mathrm{~kJ}$ (600 kcal) below that required for weight maintenance, and bodyweight scales for self monitoring. No drugs were provided or promoted.

In the first face to face visit, a 24 hour recall of dietary intake was undertaken to promote discussion around current food and 
drink intake and to allow counsellors to introduce the concept of personalised dietary change. The components of the British Heart Foundation booklet received at baseline were discussed in detail in relation to the participant's eating habits. ${ }^{23}$ Topics covered caloric reduction through decreasing portion sizes and reducing intakes of sugary drinks, alcohol, fast foods, snack foods, and processed and red meat. Higher consumption of fruits, vegetables, and whole grains were encouraged.

Counselling about personalised physical activity (according to individual ability and disability) was guided by baseline data and largely focused on brisk walking, with pedometers provided for self monitoring.

Counsellors were encouraged to concentrate on one topic (diet or physical activity) for the remainder of the first visit, on the outstanding topic in the second visit, and to review progress and revisit goals based on achievements to date at the final visit. Participants were encouraged to identify specific behavioural goals and make short term specific

"implementation-intentions." ${ }^{32}$ Telephone consultations focused on support for making lifestyle changes drawing on recent experience, checking progress, and discussing areas of success and difficulty. Advice was given on relapse (as appropriate) and support for restarting behavioural changes. Weight was self monitored through the duration of the study, reported to the counsellors, and feedback provided at each consultation. The detailed intervention protocol for all intervention procedures has been published elsewhere. ${ }^{33}$

\section{Control group}

Participants allocated to the control group after baseline measures had been obtained received no further contact until recall for three and 12 month follow-up measures.

\section{Primary and secondary outcomes}

The primary outcome was change in body weight at 12 months. Secondary outcomes were percentage weight loss, waist circumference, blood pressure, fasting cardiovascular biomarkers (levels of total cholesterol, low density lipoprotein cholesterol, high density lipoprotein cholesterol, and triglycerides), and glucose metabolism variables (fasting plasma glucose, fasting insulin, homeostasis model assessment, and glycated haemoglobin). We also assessed health behaviours (dietary and alcohol, and physical activity). We also analysed self reported psychosocial variables (self efficacy, self assessed health and quality of life, perceived risk factors for colorectal cancer, perceived acceptability of the programme, and intervention costs). The current paper reports the results of the primary outcome and the objectively measured secondary outcomes of eating and drinking habits.

\section{Analysis}

We used OpenClinica (www.OpenClinica.com) an open source, Good Clinical Practice compliant system for data management. In the primary analysis undertaken in randomised participants we used an intention to treat analysis with all available data.

We carried out multiple linear regression analyses with mixed effects models (allowing for heterogeneity in treatment effect by site) adjusted for the corresponding baseline values (for example, baseline weight for analysis of weight at follow-up), with group allocation and site as fixed effects.

For the primary outcome we also undertook a sensitivity analysis that used both repeated measures and multiple imputations for missing values (assuming data were missing at random). We examined multiple imputations to ensure that data were missing at random, then we ran and analysed 50 imputations together. We compared the results with the primary analysis to assess the impact of missing values. In addition, we carried out a prespecified subgroup analysis for socioeconomic status using fifths of Scottish index of multiple deprivation as an interaction term.

We carried out a secondary analysis on blood variables (except glycated haemoglobin) to exclude samples where participants had reported eating less than 12 hours previously.

Logistic regression was used to compare the percentage of randomised participants by group and time who achieved at least $5 \%$ and $7 \%$ weight loss, and who reduced their intake of alcohol and sugary drinks (in consumers only). Analyses controlled for site and any other baseline characteristics associated with the outcome. The data analysis was generated using SAS software, version 9.3.

\section{Results}

\section{Recruitment and follow-up}

Of the 997 screening participants approached, 492 (49\%) expressed an interest in participation; 345 (35\%) declined participation and $160(16 \%)$ did not respond (figure $\downarrow$ ). Of those who responded positively, 108 had a body mass index of $<25$, 13 responded to postal invitations to take part after recruitment to the study had closed, and 42 decided not to continue after further considering the study. The remaining 329 were randomised (163 to intervention, 166 to control). At three months 314 (94\% intervention, 97\% control) participants had completed the primary outcome measures, and $305(91 \%$ intervention, $95 \%$ control) completed the trial at 12 months $(93 \%)$.

\section{Baseline characteristics}

Participant's ages ranged from 50 to 75 years (reflecting the age for colorectal cancer screening in Scotland) (table $1 \Downarrow$, see supplementary table for baseline and clinical characteristics of only those who completed the study). Almost half ( $\mathrm{n}=155,47 \%)$ of the randomised participants had a body mass index in the obese category (>30) and $47(14 \%)$ reported a diagnosis of type 2 diabetes mellitus. Around half of the men (49\%) and 79\% of the women reported having tried to lose weight previously. Overall, $74 \%$ of the participants were men, and $35 \%$ lived in the two most deprived Scottish index of multiple deprivation fifths. The personal characteristics of the participants in each group did not differ significantly.

\section{Intervention delivery}

Data from counsellor records showed that $97 \%$ of participants in the intervention group attended all face to face consultations, with $95 \%$ completing at least five of the nine planned telephone calls and 59\% completing all nine.

\section{Primary outcome}

Mean weight loss at 12 months in the intervention group was $3.50 \mathrm{~kg}$ (SD 4.91) (95\% confidence interval 2.70 to $4.30 \mathrm{~kg}$ ) and in the control group was $0.78 \mathrm{~kg}$ (SD 3.77) (0.19 to 1.38 $\mathrm{kg}$, table $2 \Downarrow$ ). The primary analysis (with adjustment for site and baseline body weight) showed a group difference in weight loss of $2.70 \mathrm{~kg}$ ( $95 \%$ confidence interval 1.70 to $3.67 \mathrm{~kg}$ ). After multiple imputation to account for missing values, the estimated difference in weight change between the two groups remained significant at $2.69 \mathrm{~kg}$ ( 1.70 to $3.67 \mathrm{~kg}$ ). Adding deprivation status to the model had no effect on weight loss outcomes. It is 
notable that in the intervention group, weight loss continued throughout the study, with maximum weight loss achieved at 12 months. Weight loss in the control group was modest in the first three months and negligible thereafter.

\section{Secondary outcomes}

The mean percentage weight loss at 12 months in the intervention group was $3.92 \%$ (SD 5.35\%) (95\% confidence interval $3.05 \%$ to $4.78 \%$ ) compared with $0.83 \%$ (SD $4.10 \%$ ) $(0.18 \%$ to $1.47 \%)$ in the control group. The group difference was $3.04 \%$ (95\% confidence interval $2.16 \%$ to $3.92 \%$ ). The proportion of participants who lost $5 \%$ body weight was significantly higher in the intervention group than in the control group ( $36 \% v 12 \%)$, with the intervention group showing a relative risk of achieving $5 \%$ weight loss (compared with the control group) of 3.12 (95\% confidence interval 1.92 to 5.07). The proportion of participants who achieved the target of 7\% weight reduction was also higher in the intervention group (22\% $v 9 \%$, relative risk $2.5,95 \%$ confidence interval 1.40 to 4.48 ).

Significantly greater reductions in waist circumference and body mass index were also detected in the intervention group than in the control group at three and 12 months (table 2). At 12 months, the intervention group showed a significantly greater decrease in both diastolic and systolic blood pressure and blood glucose measures (table $3 \Downarrow$ ). A weak improvement in glycated haemoglobin percentage was also noted at 12 months, although this difference did not reach significance $(\mathrm{P}=0.058)$.

Statistically significant between group differences were also detected for changes in both physical activity and dietary habits (table $4 \Downarrow$ ). At three and 12 months the average step count had increased in the intervention group and decreased in the control group, resulting in a significant between group difference of 694 steps a day at 12 months. At 12 months the intervention group showed an increased time being active overall (notably in moderate activity) and by a significantly greater amount than the control group, which had become less active. The fat scores indicate a significantly greater decrease in frequency of consumption of high fat foods in the intervention group than in the control group at three and 12 months. Significant group differences were detected in the change in fibre score at three months, but this was not maintained at 12 months. However, reported mean fruit and vegetable intake increased in the intervention group to five portions a day at three and 12 months, a significantly greater change than in the control group. The proportion of participants achieving the five a day

recommendation in the intervention group increased from $61 \%$ at baseline to $81 \%$ at three months and $73 \%$ at 12 months, an increase that was greater than that in the control group (48\% to $51 \%$ and $51 \%$, respectively).

The majority of participants reported consuming sugary drinks less than once a month $(83 \%$ intervention group, $81 \%$ control group). However, of those who consumed sugary drinks more often, the odds of a reduction in intake at three months were significantly lower in the control group (odds ratio $0.12,95 \%$ confidence interval 0.02 to 0.65 , table $5 \Downarrow$ ). By 12 months the proportion of participants in the intervention group who had reduced their intake remained high, at $82 \%$, but the group difference was no longer significant.

Alcohol was commonly consumed (by $86 \%$ ), and most of these participants maintained both the frequency and the amount they consumed over the course of the study (table 5). At three months, more of the participants in the intervention group (33\%) than in the control group (22\%) had reduced their frequency of consumption, a group difference that was not maintained at 12 months. When considering the amount of alcohol consumed (rather than the frequency), more of the intervention group had significantly reduced their intake on weekdays (45\% v 30\%; odds ratio $0.50,95 \%$ confidence interval 0.26 to 0.95 ), but no group differences were noted for weekend consumption.

The average total intervention cost per participant $(n=163)$ was $£ 546$ (\$914; €662) and the average cost per participant who completed the intervention $(n=148)$ was $£ 601$.

The cost per participant consisted of intervention related literature and equipment (£38); lifestyle counsellors' face to face contact time for up to three visits (£134); travel costs, including staff time (£177); and costs not directly allocated to participants (£197). The last category included staff time required for administrative activities, which are often ignored in the costing of interventions. The travel costs and administrative costs incurred might be higher in this research study than they would be in routine practice.

Contact cost per participant was higher for the first meeting ( $£ 63$ (SD £30.53)) than for subsequent meetings ( $£ 40$ (SD $£ 20.42$ ) and $£ 38$ (SD £20.51)) with considerable variation across participants.

\section{Adverse events}

No adverse events reported by participants were considered to be related to participation in the trial.

\section{Discussion}

A 12 month, personalised, behaviourally focused weight loss programme is associated with sustained changes in body weight, physical activity, and eating and drinking habits in older adults. The average percentage weight loss was $3.9 \%$ in the intervention group, with over a third of participants achieving the clinically relevant goal of $5 \%$ weight loss, and almost a quarter achieving the programme target of $7 \%$ weight loss. These changes were accompanied by a decrease in fat intake and an increase in fruit and vegetable consumption and physical activity.

\section{Strengths and weaknesses of this study}

Lifestyle interventions in screening settings will only reach people who choose to participate, with those from less affluent areas generally being under-represented. However, a strength of this study is that the participants came from a range of sociodemographic backgrounds, and this variable had no effect on weight loss outcomes. The proportion of men in this trial (76\%) was much higher than in other weight loss trials in older adults. ${ }^{34}$ However, this is in keeping with the population presenting for colonoscopy as a result of faecal occult blood screening, ${ }^{35}$ suggesting that the screening setting provides an opportunity to engage with men, who are generally considered "hard to reach." Indeed, 51\% of the men in this study reported never having tried to lose weight previously. The continued weight loss at 12 months in the intervention participants indicates an important effect of continued (telephone) support. A weakness of the study (indeed of any study that cannot use routinely collected data) was the need for repeat measurements of body weight in the control group (to measure the primary outcome), which may itself have been enough to increase awareness of weight change and motivated some degree of weight management. The weight loss seen in the control group ran contrary to usual patterns of weight gain (which can reach $400 \mathrm{~g}$ a year), ${ }^{36}$ and it is impossible to disentangle the effect of study measurement procedures from study care procedures (booklet on weight loss, introductory letter from the consultant 
that highlighted the association between lifestyle and adenoma recurrence).

\section{Strengths and weakness in relation to other studies}

Our findings compare favourably with other weight loss programmes of diet and activity advice in older adults, which generally achieve modest (3\%) weight loss up to six months, followed by weight maintenance or gain. ${ }^{34}$ In contrast, the current programme produced continued weight reduction throughout the 12 month period with telephone support. Weight loss was less than that achieved by the more intensive Diabetes Prevention Research Group study, where 58\% of participants achieved $5 \%$ or more weight loss, but such programmes may be less feasible in routine clinical practice. ${ }^{10}$ Recent randomised controlled trials of non-drug related weight loss have highlighted the effectiveness of commercially run group programmes, which typically necessitate major input by participants (for example, one hour a week for 12 weeks). ${ }^{37}$ These have generally shown greater success than one to one programmes, but our findings show that similar results can be achieved with individualised counselling alone with considerably less participant contact and much higher retention rates. In a systematic review of weight loss in obese older adults, the drop-out rates for group programmes of diet and exercise (without individual counselling) were $11-20 \% .^{38}$ In a primary care based group programme, drop out was reported to be $55 \% .{ }^{34}$ Our retention rate of $93 \%$ compares favourably with these studies.

\section{Meaning of the study: implications for clinicians and policy makers}

Weight management programmes in secondary care are common in the context of diabetes but do not feature in the cancer screening setting. In the Scottish screening programme, 2.7\% $(n=11036)$ of participants have positive faecal occult blood test results, and, of these, $32 \%$ have adenomas, which translates to around 3500 people in Scotland having a diagnosis of adenoma each year through the programme. ${ }^{39}$

Discussing weight in the context of colorectal cancer screening is justified as obesity is a reported risk factor for recurrence of colorectal adenomas, particularly in men. It is notable that the Scottish health survey reports that $80 \%$ of Scottish men and almost $70 \%$ of Scottish women aged 55 to 74 are overweight or obese. ${ }^{40}$

Current evidence does not suggest that an adenoma diagnosis in itself is associated with change in health behaviours. ${ }^{41}$ The current findings provide an important and relevant evidence base that highlights the potential benefits of weight loss for prevention of all obesity related cancers (including breast, endometrial, and oesophageal) at a life stage where fear of cancer is high and particularly in those in whom an increased risk of disease has been identified. ${ }^{42}$

Although there is widespread recognition that health promotion is central to the provision of healthcare, ${ }^{43}$ the potential for healthcare systems (including hospitals and clinics) to promote appropriate diet, physical activity, and body weight is an area that is underdeveloped. ${ }^{44}$ Recent initiatives such as the "health promoting health service" and "every contact counts" in the United Kingdom may provide opportunities to deliver screening and prevention programmes. ${ }^{45} 46$

\section{Unanswered questions and future research}

A full cost benefit analysis is still to be undertaken. Further research is required to explore whether behaviour change and weight loss is continued beyond the intervention and to assess the impact of a fully powered, long term programme on colorectal adenomas and other obesity related comorbidities.

We thank the participants of this trial, trial manager, trial administrator, research nurses, and lifestyle counsellors, whose enthusiastic support made the trial possible.

Contributors: ASA (guarantor) had the original idea for the study and with AMC, SC, JB, MS, JR, ST, JT, AK, AL, JW, FD, and RJCS designed the trial variables and formed the investigator group that obtained the funding. ASA, AMC, ST, JT, RJCS, and SC were responsible for overseeing study implementation and data collection. PR, AMC, PN, and MM carried out the analysis. ASA, AMC, and MM drafted the manuscript, which was revised by all authors. All researchers were independent of the funders. The study sponsor and funder played no role in study design; the collection, analysis, and interpretation of data; the writing of the report; and the decision to submit the article for publication. All authors, external and internal, had full access to all of the data (including statistical reports and tables) in the study and can take responsibility for the integrity of the data and the accuracy of the data analysis.

Funding: This study was funded by the MRC National Prevention Research Initiative (www.npri.org.uk), grant award No G0802030. National Prevention Research Initiative is a national research initiative administered by the Medical Research Council made up of the following funding partners: Alzheimer's Research Trust; Alzheimer's Society; Biotechnology and Biological Sciences Research Council; Cancer Research UK; Chief Scientist Office, Scottish Government Health Directorate; Department of Health; Diabetes UK; Economic and Social Research Council; Engineering and Physical Sciences Research Council; Health and Social Care Research and Development Office for Northern Ireland; Medical Research Council; Welsh Assembly Government; and World Cancer Research Fund. Further financial support was provided by NHS Research Scotland to carry out this work. The Health Services Research Unit, University of Aberdeen, is core funded by the Chief Scientist Office of the Scottish Government Health Directorates.

Ethical approval: This study was approved by Tayside Committee on Medical Research Ethics B on 16 July 2010 (REC reference No 10/S1402/34).

Competing interests: All authors have completed the ICMJE uniform disclosure form at www.icmje.org/coi_disclosure.pdf and declare: no support from any organisation for the submitted work; no financial relationships with any organisations that might have an interest in the submitted work in the previous three years; no other relationships or activities that could appear to have influenced the submitted work with the exception of RJCS who declares his work as director of the Scottish bowel screening programme.

Transparency: The lead author (the manuscript's guarantor) affirms that the manuscript is an honest, accurate, and transparent account of the study being reported; that no important aspects of the study have been omitted; and that any discrepancies from the study as planned (and, if relevant, registered) have been explained.

Data sharing: No additional data available.

Cancer Research UK. Bowel cancer statistics. Cancer Research UK, 2013. http://info. cancerresearchuk.org/cancerstats/types/bowel/?script=true.

2 Klabunde CN, Legler JM, Warren JL, Baldwin LM, Schrag D. A refined comorbidity measurement algorithm for claims-based studies of breast, prostate, colorectal, and lung cancer patients. Ann Epidemiol 2007;17:584-90.

3 De Bruijn KM, Arends LR, Hansen BE, Leeflang S, Ruiter R, van Eijck CH. Systematic review and meta-analysis of the association between diabetes mellitus and incidence and mortality in breast and colorectal cancer. Br J Surg 2013;100:1421-9.

4 Jacobs ET, Martínez ME, Alberts DS, Jiang R, Lance P, Lowe KA, et al. Association between body size and colorectal adenoma recurrence. Clin Gastroenterol Hepatol 2007;5:982-90.

5 Sedjo RL, Byers T, Levin TR, Haffner SM, Saad MF, Tooze JA, et al. Change in body size and the risk of colorectal adenomas. Cancer Epidemiol Biomarkers Prev 2007;16:526-31. 


\section{What is already known on this topic?}

Excess body weight is a risk factor for colorectal adenomas and cancer

Teachable moments for offering lifestyle interventions can be identified within NHS settings

Weight loss programmes involving lifestyle change can achieve clinically significant weight loss but these have mostly involved women

\section{What this study adds}

Participants of colorectal cancer screening (including older men from a range of socioeconomic backgrounds) are interested in participating and committing to a 12 month lifestyle improvement and weight loss programme

An intervention of 5.25 hours of lifestyle counsellor contact time over 12 months delivered on a one to one basis resulted in continuous and significant weight loss, with improvements in blood pressure and blood glucose, over a 12 month period

Colorectal cancer screening provides an opportunity to promote and achieve weight loss in older adults who are at risk of a range of obesity related comorbidities

6 Look AHEAD Research Group, et al. Cardiovascular effects of intensive lifestyle intervention in type 2 diabetes. N Engl J Med 2013;369:145-54.

7 Knowler WC, Barrett-Connor E, Fowler SE, Hamman RF, Lachin JM, Walker EA, et al. Reduction in the incidence of type 2 diabetes with lifestyle intervention or metformin. $N$ Engl J Med 2002;346:393-403.

8 American Institute of Cancer Research and the World Cancer Research Fund. Food, nutrition, physical activity and the prevention of cancer: a global perspective. AICR, 2007. 2013. www.dietandcancerreport.org/cancer_resource center/downloads/summary/english. pdf.

9 World Cancer Research Fund (WCRF)/American Institute for Cancer Research updated Cancer preventability estimates for body fatness. WCRF International, 2013. www.wcrf. org/cancer_statistics/preventability_estimates/preventability_estimates_body_fatness. php.

10 UK Colorectal Cancer Screening Pilot Group. Results of the first round of a demonstration pilot of screening for colorectal cancer in the United Kingdom. BMJ 2004;329:133-5.

11 Steele RJC, McClemenst P, Wattling C, Libby G, Weller D, Brewster DH, et al. Interval cancers in a FOBT-based colorectal cancer population screening programme: implications for stage, gender and tumour site. Gut 2012;61:576-81.

12 Robertson DJ, Lieberan DA, Winawer SJ. Colorectal cancers soon after colonoscopy: a pooled multicohort analysis. Gut 2013; published online 21 Jun.

13 Kitahara CM, Berndt SI, de Gonazalez AB, Coleman HG, Schoen RE, Hayes RB, et al. Prospective investigation of body mass index, colorectal adenoma and colorectal cance in the prostate, lung, colorectal and ovarian screening trial. J Clin Oncol 2013;31:2450-9.

14 Yamaji Y, Okamoto M, Yoshida H, Kawabe T, Wada R, Mitsushima T, et al. The effect of body weight reduction on the incidence of colorectal adenoma. Am J Gastroenterol 2008:103-2061-7.

15 Anderson AS, Mackison D, Boath C, Steele R. Promoting changes in diet and physical activity in breast and colorectal cancer screening settings: an unexplored opportunity for endorsing healthy behaviours. Cancer Prev Res (Phila) 2013;6:165-72.

16 McBride CM, Clipp E, Peterson BL, Lipkus IM, Demark-Wahnfried W. Psychological impact of diagnosis and risk reduction among cancer survivors. Psycho Oncol 2000:9:418-27.

17 Stead M, Caswell S, Craigie AM, Eadie D, Anderson AS, BeWEL team. Understanding the potential and challenges of adenoma treatment as a prevention opportunity: insights from the BeWEL formative study. Prev Med 2012;54:97-103.

18 Dowswell G, Ryan A, Taylor A, Daley A, Freemantle N, Brookes M, et al. Designing an intervention to help people with colorectal adenomas reduce their intake of red and processed meat and increase their levels of physical activity: a qualitative study. BMC Cancer 2012;12:255

19 Larsen IK, Grotmol T, Almendingan K, Hoff G. Impact of colorectal cancer screening on future lifestyle choices: a three-year randomized controlled trial. Clin Gastroenterol Hepato 2007;5:477-83.

20 Craigie AM, Caswell S, Paterson C, Treweek S, Belch JJ, Daly F, et al. Study protocol for BeWEL: the impact of a BodyWEight and physicaL activity intervention on adults at risk of developing colorectal adenomas. BMC Public Health 2011;11:184

21 Knowler WC, Barrett-Connor E, Fowler SE, Hamman RF, Lachin JM, Walker EA, et al. Reduction in the incidence of type 2 diabetes with lifestyle intervention or metformin. $N$ Engl J Med 2002;346:393-403.

22 Caswell S, Anderson AS, Steele RJC. Bowel health to better health: a minimal contact lifestyle intervention for people at increased risk of colorectal cancer. Br J Nutr 2009;102:1541-6.

23 British Heart Foundation. So you want to lose weight for good. BHF, 2009. 2013. www. bhf.org.uk/publications/view-publication.aspx?ps $=1000807$.

24 Matthews DR, Hosker JP, Rudenski AS, Naylor BA, Treacher DF, Turner RC. Homeostasis model assessment: insulin resistance and $\beta$-cell function from fasting plasma glucose and insulin concentrations in man. Diabetologia 1985;28:412-9.

25 Mackey DC, Manini TM, Schoeller DA, Koster A, Glynn NW, Goodpaster BH, et al. Validation of an armband to measure daily energy expenditure in older adults. $J$ Gerontol A Biol Sci Med Sci 2011;66:1108-13.

26 Roe L, Strong C, Whiteside C, Neil A, Mant D. Dietary intervention in primary care: validity of the DINE method for diet assessment. Fam Pract 1994;11:375-81.

27 Cappuccio FP, Rink E, Perkins-Porras L, McKay C, Hilton S, Steptoe A. Estimation of fruit and vegetable intake using a two-item dietary questionnaire: a potential tool for primary health care workers. Nutr Metab Cardiovasc Dis 2003;13:12-9.
28 National Health Service. 5 a day portion sizes. NHS, 2011. 2013. www.nhs.uk/Livewell/ 5ADAY/Pages/Portionsizes.aspx.

29 Babor TF, de la Fuente JR, Saunders J, Grant M. AUDIT: the Alcohol Use Disorders Identification Tests: guidelines for use in primary health care. World Health Organization, 1992. 2013. http://whqlibdoc.who.int/hq/1992/WHO_PSA_92.4.pdf.

30 Scottish Government. Scottish Index of Multiple Deprivation. 2012. www.scotland.gov.uk/ Topics/Statistics/SIMD/.

31 Rollnick S, Butler C, Kinnersley S, Gregory J, Mash B. Motivational interviewing. BMJ 2010;340:1242-5.

32 Gollwitzer PM. Goal achievement: the role of intentions. Eur Rev Soc Psycho 1993;4:141-85.

33 Caswell S, Craigie AM, Wardle J, Stead M, Anderson A. Detailed protocol for the lifestyle intervention in the BeWEL randomised controlled trial of weight loss in adults who have had a colorectal adenoma. BMJ Open 2012;2.

34 Witham MD, Avenell A. Interventions to achieve long term weight loss in obese older people. A Systematic review and meta-analysis. Age Ageing 2010;39:176-84.

35 Steele RJ, McClements PL, Libby G, Black R, Morton C, Birrell J, et al. Results from the first three rounds of the Scottish demonstration pilot of FOBT screening for colorectal cancer. Gut 2009:58:530-5.

36 Romaguera D, Norat T, Vergnaud AC, Mouw T, May AM, Agudo A, et al. Mediterranean dietary patterns and prospective weight change in participants of the EPIC-PANACEA project. Am J Clin Nutr 2010;92:912-21.

37 Jolly K, Lewis A, Beach J, Denley J, Adab P, Deeks JJ, et al. Comparison of range of commercial or primary care led weight reduction programmes with minimal intervention control for weight loss in obesity: lighten up randomised controlled trial. BMJ 2011;343:d6500

38 Counterweight Project Team. Evaluation of the Counterweight Programme for obesity management in primary care: a starting point for continuous improvement. Br J Gen Pract 2008;58:548-54

39 NHS National Service Division. Scottish Bowel Screening Programme KPI 2010-2012. 2013. www.isdscotland.org/Health-Topics/Cancer/Publications/2013-08-27/KPI-Report. pdf.

40 ScotCen Social Research, University College London. Department of Epidemiology and Public Health and University of Glasgow. MRC/CSO Social and Public Health Sciences Unit, Scottish Health Survey, 2012. UK Data Archive, Nov 2013. SN: 7417. http://dx.doi. org/10.5255/UKDA-SN-7417-1.

41 Miles A, Wardle J, McCaffery K, Williamson S, Atkin W. The effects of colorectal cance screening on health attitudes and practices. Cancer Epidemiol Biomarkers Prev 2003:12:651-5.

42 World Health Organization. Standards for health promotion in hospitals. WHO, 2004. www.euro.who.int/data/assets/pdf_file/0006/99762/e82490.pdf.

43 Birks S, Peeters A, Backholer K, O'Brien P, Brown W. A systematic review of the impact of weight loss on cancer incidence and mortality. Obes Rev 2012;13:868-91.

44 Royal College of Physicians. Action on obesity: comprehensive care for all. Report of a working party. Royal College of Physicians, 2013. www.rcplondon.ac.uk/sites/default/files/ action-on-obesity.pdf.

45 Health Promoting Health Service. Overview (2009). 2013. www.healthscotland.com/ documents/4128.aspx.

46 The NHS's role in the public's health. A report from the NHS Future Forum. 2013. www. gov.uk/government/uploads/system/uploads/attachment_data/file/216423/dh_132114. pdf.

\section{Accepted: 20 February 2014}

\section{Cite this as: BMJ 2014;348:g1823}

This is an Open Access article distributed in accordance with the Creative Commons Attribution Non Commercial (CC BY-NC 3.0) license, which permits others to distribute, remix, adapt, build upon this work non-commercially, and license their derivative works on different terms, provided the original work is properly cited and the use is non-commercial. See: http://creativecommons.org/licenses/by-nc/3.0/. 


\section{Tables}

Table 1| Baseline and clinical characteristics at randomisation. Values are numbers (percentages) unless stated otherwise

\section{Characteristics}

Age (years), mean (SD), range

Men

Marital status:

\begin{tabular}{|c|c|c|c|}
\hline Single & $7(4)$ & $14(8)$ & $21(6)$ \\
\hline Married or cohabiting & $130(80)$ & $132(80)$ & $262(80)$ \\
\hline Divorced, widowed, or separated & $26(16)$ & $20(12)$ & $46(14)$ \\
\hline \multicolumn{4}{|l|}{ Ethnicity: } \\
\hline White & $163(100)$ & $164(99)$ & $327(99)$ \\
\hline Asian or Asian British & $0(0)$ & $1(1)$ & $1(0.3)$ \\
\hline Other & $0(0)$ & $1(1)$ & $1(0.3)$ \\
\hline \multicolumn{4}{|l|}{ Highest educational qualification: } \\
\hline Primary school & $1(1)$ & $2(1)$ & $3(1)$ \\
\hline Secondary school & $63(39)$ & $65(39)$ & $128(39)$ \\
\hline Other professional or technical qualification after school & $76(47)$ & $77(46)$ & $153(47)$ \\
\hline University or postgraduate degrees & $23(14)$ & $22(13)$ & $45(14)$ \\
\hline \multicolumn{4}{|l|}{ Employment status: } \\
\hline Retired & $90(55)$ & $97(58)$ & $187(57)$ \\
\hline Employed full time & $45(28)$ & $41(25)$ & $86(26)$ \\
\hline Employed part time & $18(11)$ & $14(8)$ & $32(10)$ \\
\hline Unemployed & $2(1)$ & $10(6)$ & $12(4)$ \\
\hline Other & $8(5)$ & $4(2)$ & $12(4)$ \\
\hline \multicolumn{4}{|l|}{ Scottish index of multiple deprivation (fifths): } \\
\hline 1 (most deprived) & $25(15)$ & $29(18)$ & $54(16)$ \\
\hline 2 & $33(20)$ & $28(17)$ & $61(19)$ \\
\hline 3 & $26(16)$ & $33(20)$ & $59(18)$ \\
\hline 4 & $39(24)$ & $45(27)$ & $84(26)$ \\
\hline 5 (least deprived) & $40(25)$ & $31(19)$ & $71(22)$ \\
\hline
\end{tabular}


Table 2| Changes in anthropometric measures from baseline to three and 12 months, by treatment group. Values are means $(95 \%$ confidence intervals) unless stated otherwise

\begin{tabular}{|c|c|c|c|c|c|c|c|}
\hline \multirow{2}{*}{$\begin{array}{l}\text { Baseline and follow-up } \\
\text { measures }\end{array}$} & \multicolumn{3}{|c|}{ Intervention group } & \multicolumn{3}{|c|}{ Control group } & \multirow{2}{*}{$\begin{array}{c}\text { Between group differences*, } \mathbf{P} \\
\text { value }\end{array}$} \\
\hline & No & Mean (SD) & Difference to baseline & No & Mean (SD) & Difference to baseline & \\
\hline \multicolumn{8}{|l|}{ Body weight $(\mathrm{kg})$ : } \\
\hline Baseline & 163 & $90.2(14.9)$ & - & 166 & $88.4(14.3)$ & - & - \\
\hline 3 months & 153 & $88.7(15.0)$ & $-2.10(-2.57$ to -1.63$)$ & 161 & $88.1(14.2)$ & $-0.67(-1.00$ to -0.34$)$ & $1.42(0.84$ to 1.99$),<0.001$ \\
\hline 12 months & 148 & $87.2(15.7)$ & $-3.50(-4.30$ to -2.71$)$ & 157 & $88.1(14.2)$ & $-0.78(-1.38$ to -0.19$)$ & 2.69 (1.70 to 3.67$),<0.001$ \\
\hline \multicolumn{8}{|l|}{ Body mass indext: } \\
\hline Baseline & 163 & $31.0(4.5)$ & - & 166 & $30.4(3.9)$ & - & - \\
\hline 3 months & 153 & $30.4(4.6)$ & $-0.72(-0.89$ to -0.56$)$ & 161 & $30.2(4.0)$ & $-0.23(-0.34$ to -0.11$)$ & $0.48(0.20$ to 0.75$), 0.0007$ \\
\hline 12 months & 148 & $29.9(4.8)$ & $-1.22(-1.50$ to -0.94$)$ & 157 & $30.1(3.8)$ & $-0.27(-0.47$ to -0.07$)$ & $0.92(0.64$ to -1.20$),<0.001$ \\
\hline \multicolumn{8}{|l|}{ Waist circumference $(\mathrm{cm})$ : } \\
\hline Baseline & 163 & $104.7(10.9)$ & - & 166 & $103.9(10.9)$ & - & - \\
\hline 3 months & 153 & $102.6(11.1)$ & $-2.55(-3.14$ to -1.97$)$ & 159 & $102.7(11.1)$ & $-1.34(-1.82$ to -0.87$)$ & $1.17(0.25$ to 2.10$), 0.015$ \\
\hline 12 months & 145 & $100.2(12.0)$ & $-4.91(-5.79$ to -4.03$)$ & 157 & $102.1(11.1)$ & $-2.16(-2.85$ to -1.47$)$ & $2.68(1.74$ to 3.62$),<0.001$ \\
\hline
\end{tabular}

${ }^{*}$ Adjusted for baseline value and site.

†Defined as (weight $(\mathrm{kg}) /$ height $\left.(\mathrm{m})^{2}\right)$. 
Table 3| Changes in cardiovascular risk and glucose metabolism biomarkers (secondary analyses). Values are means (95\% confidence intervals) unless stated otherwise

\begin{tabular}{|c|c|c|c|c|c|c|c|c|}
\hline \multirow[b]{2}{*}{ Measures } & \multicolumn{2}{|c|}{ Baseline } & \multicolumn{2}{|c|}{3 months } & \multicolumn{2}{|c|}{12 months } & \multicolumn{2}{|c|}{ Between group differences, $P$ value } \\
\hline & No & Mean (SD) & No & Mean (SD) & No & Mean (SD) & 3 months* & 12 months* \\
\hline \multicolumn{9}{|c|}{ Systolic blood pressure $(\mathrm{mm} \mathrm{Hg})$ : } \\
\hline Intervention & 163 & $143(17.3)$ & 153 & $139(17.7)$ & 148 & $138(17.8)$ & \multirow{2}{*}{$\begin{array}{c}1.3(-1.6 \text { to } 4.2) \\
0.365\end{array}$} & \multirow{2}{*}{$\begin{array}{c}3.8(0.9 \text { to } 6.7), \\
0.011\end{array}$} \\
\hline Control & 166 & $142(18.2)$ & 160 & $139(16.7)$ & 155 & $142(17.5)$ & & \\
\hline \multicolumn{9}{|c|}{ Diastolic blood pressure $(\mathrm{mm} \mathrm{Hg})$ : } \\
\hline Intervention & 163 & $84(9.6)$ & 153 & $82(9.9)$ & 148 & $81(9.7)$ & \multirow{2}{*}{$\begin{array}{c}1.8(0.2 \text { to } 3.3), \\
0.027\end{array}$} & \multirow{2}{*}{$\begin{array}{c}1.8(0.2 \text { to } 3.3) \\
0.031\end{array}$} \\
\hline Control & 166 & $84(10.3)$ & 160 & $83(9.4)$ & 155 & $83(9.6)$ & & \\
\hline \multicolumn{9}{|c|}{ Total cholesterol (mmol/L): } \\
\hline Intervention & 144 & $5.17(1.23)$ & 126 & $4.94(1.21)$ & 125 & $4.83(1.06)$ & \multirow{2}{*}{$\begin{array}{c}0.04(-0.13 \text { to } 0.21) \\
0.624\end{array}$} & \multirow{2}{*}{$\begin{array}{c}0.10(-0.07 \text { to } 0.27) \\
0.234\end{array}$} \\
\hline Control & 150 & $5.12(1.22)$ & 135 & $4.90(1.14)$ & 131 & $4.92(1.17)$ & & \\
\hline \multicolumn{9}{|c|}{ HDL cholesterol (mmol/L): } \\
\hline Intervention & 144 & $1.36(0.36)$ & 126 & $1.32(0.33)$ & 125 & $1.37(0.34)$ & \multirow{2}{*}{$\begin{array}{c}0.01(-0.05 \text { to } 0.06) \\
0.808\end{array}$} & \multirow{2}{*}{$\begin{array}{c}-0.02(-0.07 \text { to } \\
0.03), 0.466\end{array}$} \\
\hline Control & 150 & $1.36(0.39)$ & 135 & $1.37(0.43)$ & 131 & $1.37(0.39)$ & & \\
\hline \multicolumn{9}{|c|}{ LDL cholesterol (mmol/L): } \\
\hline Intervention & 141 & $3.05(1.07)$ & 122 & $2.86(1.04)$ & 124 & $2.76(0.92)$ & \multirow{2}{*}{$\begin{array}{c}0.06(-0.09 \text { to } 0.21) \\
0.459\end{array}$} & \multirow{2}{*}{$\begin{array}{c}0.11(-0.04 \text { to } 0.26) \\
0.160\end{array}$} \\
\hline Control & 147 & $2.97(1.07)$ & 133 & $2.81(1.03)$ & 129 & $2.80(1.04)$ & & \\
\hline \multicolumn{9}{|c|}{ Triglycerides (mmol/L): } \\
\hline Intervention & 144 & $1.70(1.13)$ & 126 & $1.69(1.20)$ & 125 & $1.51(0.87)$ & \multirow{2}{*}{$\begin{array}{c}-0.05(-0.21 \text { to } \\
0.11), 0.568\end{array}$} & \multirow{2}{*}{$\begin{array}{c}0.04(-0.12 \text { to } 0.20) \\
0.591\end{array}$} \\
\hline Control & 150 & $1.78(1.11)$ & 135 & $1.65(1.00)$ & 131 & $1.66(1.02)$ & & \\
\hline \multicolumn{9}{|c|}{ Glucose (mmol/L): } \\
\hline Intervention & 142 & $6.11(2.02)$ & 127 & $5.74(1.57)$ & 125 & $5.68(1.38)$ & \multirow{2}{*}{$\begin{array}{c}0.29(0.03 \text { to } 0.56) \\
0.031\end{array}$} & \multirow{2}{*}{$\begin{array}{c}0.27(0.01 \text { to } 0.54) \\
0.045\end{array}$} \\
\hline Control & 149 & $6.12(1.93)$ & 134 & $6.11(2.06)$ & 132 & $6.08(1.67)$ & & \\
\hline \multicolumn{9}{|c|}{ Insulin $(\mathrm{mmol} / \mathrm{L})$ : } \\
\hline Intervention & 104 & $11.12(8.27)$ & 88 & $11.41(12.50)$ & 74 & $12.77(11.05)$ & \multirow{2}{*}{$\begin{array}{c}-0.36(-2.93 \text { to } \\
2.21), 0.784\end{array}$} & \multirow{2}{*}{$\begin{array}{c}-0.32(-3.02 \text { to } \\
2.39), 0.818\end{array}$} \\
\hline Control & 110 & $10.17(8.82)$ & 90 & $10.60(9.67)$ & 79 & $13.48(10.21)$ & & \\
\hline Homeostasis I & & & & & & & & \\
\hline Intervention & 103 & $3.25(3.10)$ & 88 & $3.42(5.57)$ & 74 & $3.29(3.16)$ & $-0.32(-1.31$ to & $0.43(-0.62$ to 1.48$)$ \\
\hline Control & 109 & $2.81(2.79)$ & 90 & $2.91(3.14)$ & 79 & $3.72(3.18)$ & $0.67), 0.521$ & 0.422 \\
\hline Glycated haen & & & & & & & & \\
\hline Intervention & 149 & $6.02(1.17)$ & 126 & $5.98(1.18)$ & 123 & $5.82(0.75)$ & $0.05(-0.08$ to 0.18$)$ & $0.13(-0.004$ to \\
\hline Control & 151 & $6.03(1.07)$ & 135 & $6.08(1.21)$ & 130 & $6.03(0.96)$ & 0.469 & $0.26), 0.058$ \\
\hline
\end{tabular}

HDL=high density lipoprotein cholesterol; LDL=low density lipoprotein cholesterol.

${ }^{*}$ Adjusted for baseline value and site. 


\begin{tabular}{|c|c|c|c|c|c|c|c|c|}
\hline \multirow[b]{2}{*}{ Measures } & \multicolumn{2}{|r|}{ Baseline } & \multicolumn{2}{|r|}{3 months } & \multicolumn{2}{|c|}{12 months } & \multicolumn{2}{|c|}{ Between group differences, $\mathrm{P}$ value } \\
\hline & No & Mean (SD) & No & Mean (SD) & No & Mean (SD) & 3 months* & 12 months* \\
\hline \multicolumn{9}{|c|}{ Daily average physical activity } \\
\hline \multicolumn{9}{|c|}{ Time spent active (mins): } \\
\hline Intervention & 156 & $82(62.3)$ & 145 & $88(56.6)$ & 140 & $89(65.3)$ & \multirow{2}{*}{$-3.7(-14.5$ to 7.1$), 0.500$} & \multirow{2}{*}{$\begin{array}{c}-12.9(-23.8 \text { to }-1.9) \\
0.021\end{array}$} \\
\hline Control & 157 & 79 (55.9) & 150 & $80(62.4)$ & 148 & $74(62.0)$ & & \\
\hline \multicolumn{9}{|c|}{ Time spent in sedentary activity (mins): } \\
\hline Intervention & 153 & $1287(130.6)$ & 141 & $1274(141.5)$ & 137 & $1275(175.5)$ & \multirow[t]{2}{*}{3.5 (-29.3 to 36.2$), 0.835$} & \multirow{2}{*}{$\begin{array}{c}17.1(-15.8 \text { to } 50.0) \\
0.308\end{array}$} \\
\hline Control & 153 & $1299(144.8)$ & 144 & $1296(136.2)$ & 144 & $1296(155.1)$ & & \\
\hline \multicolumn{9}{|c|}{ Time spent in moderate activity (mins): } \\
\hline Intervention & 153 & $81(58.0)$ & 141 & $87(54.9)$ & 137 & $86(63.4)$ & \multirow[t]{2}{*}{$-5.6(-16.3$ to 5.1$), 0.305$} & \multirow{2}{*}{$\begin{array}{c}-10.9(-21.7 \text { to }-0.1) \\
0.047\end{array}$} \\
\hline Control & 153 & $77(53.7)$ & 144 & $78(60.6)$ & 144 & $73(60.7)$ & & \\
\hline \multicolumn{9}{|c|}{ Time spent in vigorous activity (mins) } \\
\hline Intervention & 153 & $2(11.3)$ & 141 & $2(3.2)$ & 137 & $1(3.0)$ & \multirow[t]{2}{*}{$-0.05(-1.0$ to 0.9$), 0.915$} & \multirow[t]{2}{*}{0.3 (-0.6 to 1.3$), 0.53$} \\
\hline Control & 153 & $2(4.3)$ & 144 & $2(4.5)$ & 144 & $2(4.9)$ & & \\
\hline \multicolumn{9}{|l|}{ Step count: } \\
\hline Intervention & 156 & 8429 (3995) & 145 & $8994(4430)$ & 140 & $8697(4404)$ & \multirow[t]{2}{*}{$-619(-1241$ to 3$), 0.051$} & \multirow{2}{*}{$\begin{array}{c}-694(-1321 \text { to }-67) \\
0.030\end{array}$} \\
\hline Control & 157 & 7734 (3538) & 150 & $7753(3833)$ & 148 & $7460(3873)$ & & \\
\hline \multicolumn{9}{|l|}{ Dietary intake } \\
\hline \multicolumn{9}{|c|}{ Fat consumption score: } \\
\hline Intervention & 163 & $30(10.6)$ & 152 & $24(8.5)$ & 146 & $24(7.4)$ & \multirow[t]{2}{*}{$4.6(2.9$ to 6.3$),<0.001$} & \multirow[t]{2}{*}{$3.8(2.1$ to 5.6$),<0.001$} \\
\hline Control & 166 & $32(10.6)$ & 159 & $29(10.6)$ & 156 & $28(10.3)$ & & \\
\hline \multicolumn{9}{|c|}{ Unsaturated fat score: } \\
\hline Intervention & 161 & $9(1.6)$ & 152 & $9(1.4)$ & 147 & $9(1.2)$ & \multirow[t]{2}{*}{$-0.2(-0.5$ to 0.1$), 0.117$} & \multirow[t]{2}{*}{$-0.2(-0.5$ to 0.1$), 0.154$} \\
\hline Control & 165 & $9(1.7)$ & 160 & $9(1.7)$ & 156 & $9(1.5)$ & & \\
\hline \multicolumn{9}{|c|}{ Fibre food consumption score: } \\
\hline Intervention & 163 & $33(10.0)$ & 153 & $35(10.6)$ & 148 & $33(10.4)$ & $-2.6(-4.4$ to -0.8$), 0.005$ & $-0.4(-2.3$ to 1.4$), 0.669$ \\
\hline Control & 166 & $32(9.8)$ & 161 & $32(9.3)$ & 157 & $32(9.1)$ & & \\
\hline Fruit and vege & & & & & & & & \\
\hline Intervention & 163 & $4(2.2)$ & 153 & $5(2.2)$ & 148 & $5(2.4)$ & $-0.9(-1.3$ to -0.4$)$ & $-0.8(-1.2$ to -0.3$)$ \\
\hline Control & 166 & $4(2.2)$ & 161 & $4(2.1)$ & 157 & $4(2.4)$ & & \\
\hline
\end{tabular}

*Adjusted for baseline value and site. 
Table 5| Changes in sugary drink and alcohol consumption in consumers only. Values are odds ratios (95\% confidence intervals) unless stated otherwise

\begin{tabular}{|c|c|c|c|c|c|c|}
\hline \multirow[b]{2}{*}{$\begin{array}{l}\text { Sugary drinks and alcohol } \\
\text { consumption }\end{array}$} & \multicolumn{2}{|r|}{3 months } & \multicolumn{2}{|c|}{12 months } & \multicolumn{2}{|c|}{ Between group differences, $P$ value } \\
\hline & No & $\begin{array}{c}\text { No (\%) with reduced } \\
\text { intake }\end{array}$ & No & $\begin{array}{l}\text { with reduced } \\
\text { intake }\end{array}$ & 3 months* & 12 months* \\
\hline \multicolumn{7}{|l|}{ Sugary drinks: } \\
\hline Intervention & 23 & $20(87)$ & 22 & $18(82)$ & \multirow{2}{*}{$\begin{array}{c}0.12(0.02 \text { to } 0.65) \\
0.014\end{array}$} & \multirow{2}{*}{$\begin{array}{c}0.67(0.14 \text { to } 3.20) \\
0.616\end{array}$} \\
\hline Control & 27 & $16(59)$ & 28 & $21(75)$ & & \\
\hline \multicolumn{7}{|l|}{ Alcohol: } \\
\hline \multicolumn{7}{|l|}{ Frequency: } \\
\hline Intervention & 132 & $44(33)$ & 128 & $38(30)$ & \multirow{2}{*}{$\begin{array}{c}0.56(0.32 \text { to } 0.97) \\
0.039\end{array}$} & \multirow{2}{*}{$\begin{array}{c}0.64(0.37 \text { to } 1.13) \\
0.124\end{array}$} \\
\hline Control & 138 & $30(22)$ & 135 & $29(21)$ & & \\
\hline \multicolumn{7}{|l|}{ Weekday consumption: } \\
\hline Intervention & 88 & $32(36)$ & 85 & $38(45)$ & \multirow{2}{*}{$\begin{array}{c}0.72 \text { (0.38 to } 1.37) \\
0.319\end{array}$} & \multirow{2}{*}{$\begin{array}{c}0.50(0.26 \text { to } 0.95) \\
0.034\end{array}$} \\
\hline Control & 91 & $28(31)$ & 90 & $27(30)$ & & \\
\hline \multicolumn{7}{|l|}{ Weekend consumption: } \\
\hline Intervention & 128 & $37(29)$ & 124 & $27(22)$ & \multirow{2}{*}{$\begin{array}{c}0.97 \text { (0.60 to } 1.67) \\
0.904\end{array}$} & \multirow{2}{*}{$\begin{array}{c}1.32(0.73 \text { to } 2.38), \\
0.363\end{array}$} \\
\hline Control & 131 & $37(28)$ & 128 & $35(27)$ & & \\
\hline
\end{tabular}

*Adjusted for site and any other baseline characteristics associated with intake. 


\section{Figure}

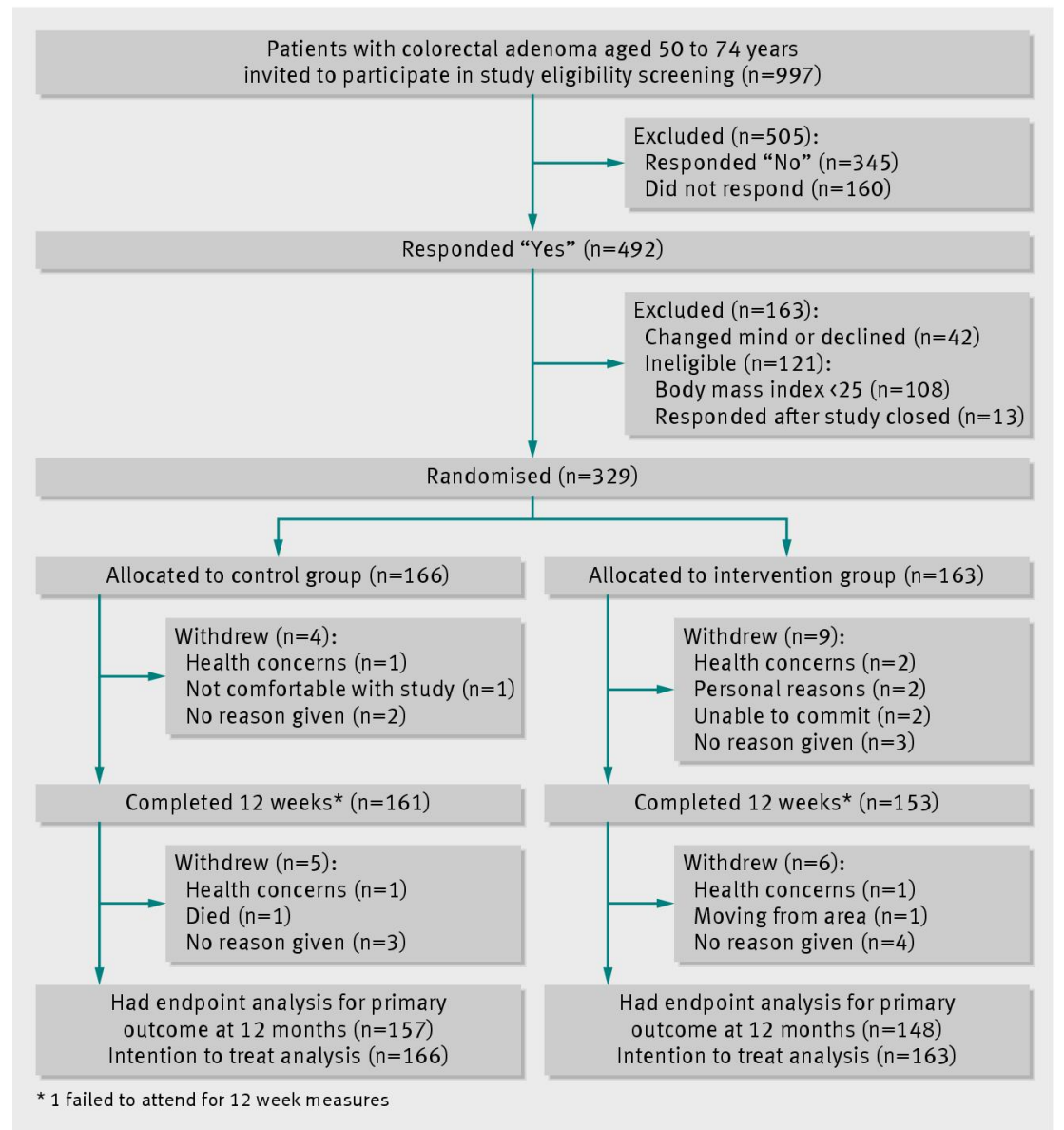

Trial recruitment and retention 